\title{
Investigation on Properties of Cement Bitumen Emulsion Mortars (CBEM) in Consideration of Emulsifier Types
}

\author{
Zhuoran Liu, ${ }^{1}$ Jinyang Huo, ${ }^{1}$ and Zhenjun Wang $\mathbb{D}^{1,2}$ \\ ${ }^{1}$ School of Materials Science and Engineering, Chang'an University, Xi'an 710061, China \\ ${ }^{2}$ Engineering Research Center of Pavement Materials, Ministry of Education of China, Chang'an University, Xi'an 710061, China
}

Correspondence should be addressed to Zhenjun Wang; zjwang@chd.edu.cn

Received 24 July 2020; Revised 28 October 2020; Accepted 16 November 2020; Published 23 November 2020

Academic Editor: Meng Guo

Copyright (c) 2020 Zhuoran Liu et al. This is an open access article distributed under the Creative Commons Attribution License, which permits unrestricted use, distribution, and reproduction in any medium, provided the original work is properly cited.

In order to investigate the influences of emulsifier types on properties of cement bitumen emulsion mortars (CBEM), anionic and cationic emulsifiers were used to prepare CBEM in this work. Influences of anionic and cationic bitumen emulsions on workability, mechanical properties, and viscoelastic property of CBEM were studied. The workability of CBEM was evaluated by fluidity and extensibility tests. The mechanical properties were assessed by compressive strength and flexural strength tests. XRD was used to analyze the phase before and after bitumen emulsion was added. The viscoelastic property was studied by a dynamic mechanical analyzer (DMA). The results show that CBEM prepared by cationic bitumen emulsion (CBE) has better workability. The mechanical properties of CBEM are negatively affected by bitumen emulsion. The impact on the compressive strength of CBEM prepared by CBE is higher. Bitumen emulsion can significantly improve the viscoelastic property of CBEM. With the increase of bitumen emulsion dosage, the loss factor of CBEM increases. The viscoelastic property at low frequency is better than that at high frequency. In contrast to CBEM prepared by CBE, CBEM prepared with anionic bitumen emulsion (ABE) possesses better viscoelastic property.

\section{Introduction}

Cement bitumen emulsion mortars (CBEM) are prepared by cement, bitumen emulsion, water, fine aggregate, and admixtures. The elasticity of bitumen materials and high strength of cement materials are combined in CBEM, which have been widely used in high-speed railway construction. Nowadays, more and more attentions are paid to CBEM [1-4]. Pure bitumen and bitumen emulsion have different influences on the property of CBEM [5]. Studies have shown that anionic bitumen emulsion (ABE) has retarding effect on hydration of cement in CBEM [6]. As the ratio of bitumen to cement increases, the setting time of the new bitumen emulsion cement paste increases [7]. Generally speaking, the cement hydration is insufficient when the content of the emulsifier is low, but the cement hydration is more complete when the content of the emulsifier is high. It is mainly due to the demulsification process of bitumen emulsion in CBEM [8]. Another study shows that the presence of the emulsifier can accelerate the hydration of cement [9]. The demulsification process of bitumen emulsion can be studied and evaluated by ultraviolet spectroscopy [10].

Because of the influence of bitumen emulsion on the mechanical properties of CBEM, the mechanical properties of CBEM have been widely concerned by researchers $[11,12]$. The mechanical behavior of cement bitumen blends is affected by the bitumen/cement $(\mathrm{B} / \mathrm{C})$ ratio [13]. In addition, environmental factors also have a great influence on the mechanical properties of CBEM [14]. Microwave heating environment has an effect on the early strength of CBEM [15]. High-temperature environment has a certain negative impact on the compressive strength and elastic modulus of CBEM [16]. CBEM in acidic environment for a long time can also affect its mechanical properties. The compressive strength of CBEM soaked in ammonium nitrate solution has a certain decrease [17]. Moreover, the deterioration of its external surface seriously affects the railway traffic safety [18]. In addition, the higher 
$\mathrm{B} / \mathrm{C}$ ratio can promote the bond strength between $\mathrm{CBEM}$ and concrete slab [19]. Bitumen emulsion has a certain effect on the properties of CBEM. Some studies have shown that $\mathrm{CBEM}$ with a high $\mathrm{B} / \mathrm{C}$ ratio has better workability $[20,21]$. In addition, the sand-to-cement ratio of CBEM has a certain influence on its flow property [22]. The workability of CBEM can be evaluated by orthogonal test, and CBEM with excellent workability can be prepared [23].

As a viscoelastic material, the viscoelastic property of CBEM should be paid more attention to. The results show that the viscoelastic property of CBEM is the main reason for decreasing the track slab degumming phenomenon [24]. The addition of superplasticizers can stabilize the viscosity of CBEM [25]. However, the superplasticizers have a negative effect on the plastic viscosity of bitumen emulsion [26]. Dynamic mechanical analysis (DMA) is widely used as a method to evaluate the viscoelastic property of asphaltic materials [27-29]. The stress relaxation stage of CBEM can be explored by a dynamic mechanical thermal spectrometer [30]. In addition, the $\mathrm{B} / \mathrm{C}$ ratio has an effect on the viscoelastic property of CBEM [31], and the viscosity of bitumen emulsion increases sharply with the addition of cement [32]. The type of emulsifier also has a certain influence on the viscoelastic property of CBEM [33]. In addition, cement can improve the microstructure of CBEM, so as to improve the adhesion between bitumen and aggregate [34].

In this paper, the influences of emulsifier types on the workability, mechanical properties, and viscoelastic property of CBEM were studied. The workability of CBEM was evaluated by fluidity and extensibility tests. The CBE and $\mathrm{ABE}$ were used to improve the workability of CBEM. The mechanical properties of CBEM were evaluated by compressive strength and flexural strength tests. The influences of $\mathrm{CBE}$ and $\mathrm{ABE}$ on the mechanical properties of CBEM are discussed. Dynamic mechanical analysis (DMA) was used to study the influence of different bitumen emulsion content, loading frequency, and bitumen emulsion types on the viscoelastic properties of CBEM. The CBE and ABE were used to improve the viscoelastic properties of CBEM. The CBEM samples with bitumen emulsions prepared by two different emulsifiers are treated with XRD because the mechanism of the anion-cation bitumen emulsion in the demulsification process is different.

\section{Raw Materials and Test Methods}

2.1. Raw Materials. Composite Portland cement was used and its properties are shown in Table 1. Properties of bitumen are shown in Table 2. The properties of fine aggregate are shown in Table 3. Cationic emulsifier and anionic emulsifier were used as emulsifiers, and the properties of the emulsifiers are shown in Table 4. The organosilicon defoaming agent was used as a defoaming agent and its properties are shown in Table 5.

2.2. Preparation of CBEM. Firstly, cationic and anionic emulsifiers were used to prepare bitumen emulsion with solid content of $60 \%$. The emulsion soap liquid was set up by
TABle 1: Properties of composite Portland cement.

\begin{tabular}{lcc}
\hline \multicolumn{1}{c}{ Properties } & Test results \\
\hline Density $\left(\mathrm{g} / \mathrm{cm}^{3}\right)$ & 2.923 & \\
Average pore size $(\mu \mathrm{m})$ & 20.689 & \\
Compressive strength $(\mathrm{MPa})$ & $3 \mathrm{~d}$ & 18.9 \\
& $28 \mathrm{~d}$ & 32.2 \\
Flexural strength $(\mathrm{MPa})$ & $3 \mathrm{~d}$ & 2.5 \\
& $28 \mathrm{~d}$ & 5.7 \\
Setting time $(\mathrm{MPa})$ & Initial setting & 123 \\
& Final setting & 169 \\
\hline
\end{tabular}

TABle 2: Properties of original bitumen.

\begin{tabular}{lcc}
\hline Properties & Specification & $\begin{array}{c}\text { Test } \\
\text { values }\end{array}$ \\
\hline $\begin{array}{l}\text { Needle penetration }\left(25^{\circ} \mathrm{C}, 100 \mathrm{~g}, 5 \mathrm{~s}\right) \\
(0.1 \mathrm{~mm})\end{array}$ & $60-80$ & 78 \\
Ductility $\left(5^{\circ} \mathrm{C}, 5 \mathrm{~cm} / \mathrm{min}\right)(\mathrm{cm})$ & $\geq 40$ & 47 \\
Softening point $\left({ }^{\circ} \mathrm{C}\right)$ & $\geq 50$ & 53.4 \\
Density $\left(15^{\circ} \mathrm{C}, \mathrm{g} / \mathrm{cm}^{3}\right)$ & - & 1.036 \\
Wax content $(\%)$ & - & 1.4 \\
\hline
\end{tabular}

TABle 3: Properties of fine aggregate.

\begin{tabular}{lc}
\hline Properties & Test results \\
\hline Apparent density $\left(\mathrm{g} / \mathrm{cm}^{3}\right)$ & 2.605 \\
Sediment percentage $(\%)$ & 0.5 \\
Fineness modulus & 2.44 \\
Bulk density $\left(\mathrm{g} / \mathrm{cm}^{3}\right)$ & 1.465 \\
Water absorption $(\%)$ & 1.5 \\
\hline
\end{tabular}

TABle 4: Properties of emulsifiers.

\begin{tabular}{lccc}
\hline Types & Component & $\begin{array}{c}\text { Density } \\
\left(25^{\circ} \mathrm{C}, \mathrm{g} / \mathrm{cm}^{3}\right)\end{array}$ & $\begin{array}{c}\text { Viscosity } \\
\left(25^{\circ} \mathrm{C}, \mathrm{Pa} \cdot \mathrm{s}\right)\end{array}$ \\
\hline $\mathrm{CBE}$ & Quaternary ammonium salt & 1.180 & 9.13 \\
$\mathrm{ABE}$ & Sodium hexadecyl acetate & 1.210 & 8.75 \\
\hline
\end{tabular}

TABle 5: Properties of defoaming agent.

\begin{tabular}{lc}
\hline Project & Results \\
\hline Appearance & White liquid at normal temperature \\
Solid content (\%) & $60 \%$ \\
pH value & $6-8$ \\
Stability & No stratification and no precipitation \\
\hline
\end{tabular}

$400 \mathrm{~g}$ water $\left(60^{\circ} \mathrm{C}\right), 20-24 \mathrm{~g}$ emulsifier (cationic/anionic), and $15 \mathrm{~g} \mathrm{CaCl}_{2}$. The $\mathrm{pH}$ value of the cationic emulsifier was adjusted to $2-3$ by $\mathrm{HCl}$, and the anionic emulsifier was adjusted to $9-10$ by $\mathrm{NaOH}$. After melting bitumen to the temperature of $180^{\circ} \mathrm{C}$, the emulsifier was first poured into the colloid mill, and the melted bitumen with a mass of $600 \mathrm{~g}$ was poured into the running colloid mill and emulsified to prepare cationic bitumen emulsion (CBE) and anionic bitumen emulsion $(\mathrm{ABE})$. The water-cement ratio $(\mathrm{w} / \mathrm{c})$ was 0.4 (including the water content in bitumen emulsion), the sand-cement ratio $(\mathrm{s} / \mathrm{c})$ was 1.2 , and the amount of 
defoaming agent was $2 \%$ of the water weight. The different bitumen emulsion content was allocated according to the cement quality of $0-50 \%$ with $5 \%$ interval. Firstly, the dry materials (cement and sand), water, and bitumen emulsion were mixed into an agitator. Then, the defoaming agent of $2.0 \%$ water quality was added to the agitator. The mixing process is slowly stirred by $20 \mathrm{r} / \mathrm{min}-30 \mathrm{r} / \mathrm{min}$ for 5 minutes to avoid more bubbles. The mortars were put into steel modules at room temperature for maintenance. After 24 hours, the samples were cured for $3 \mathrm{~d}, 7 \mathrm{~d}$, or $28 \mathrm{~d}$ at the temperature of $20^{\circ} \mathrm{C}$ and relative humidity of $90 \%$. The flowchart of CBEM preparation is shown in Figure 1.

\subsection{Experiments}

2.3.1. Workability Tests. Fluidity and extensibility were tested to evaluate CBEM workability. The fluidity was tested by a fluidity tester. The funnel was wetted and placed on the funnel rack. The axis of the hopper was vertical to the ground, and the container bucket was placed below the funnel. The funnel hole was blocked by fingers and 1L CBEM was poured into the funnel slowly and evenly. Release the fingers and start the stopwatch at the same time and then measure the time required for the completion of CBEM in the funnel. The extensibility was tested by the relevant national standard method. The surface of the glass plate and the extension cylinder were wetted and the cylinder was vertical in the middle of the glass plate. The mixed CBEM was filled into the cylinder till the upper edge of the cylinder. The cylinder was raised by $15 \pm 2 \mathrm{~cm}$ vertically and the height was kept for $10 \mathrm{~s}$. Meanwhile, the time of extensibility of CBEM reaching $280 \mathrm{~mm}$ was recorded by stopwatch. After CBEM stopped flowing, the extension diameter of two perpendicular directions was measured.

2.3.2. Mechanical Properties Tests. Compressive strength and flexural strength of the CBEM with $3 \mathrm{~d}, 7 \mathrm{~d}$, and $28 \mathrm{~d}$ curing ages were tested according to the instructions for Type II cement bitumen emulsion mortar [35]. The sizes of specimens were $40 \mathrm{~mm} \times 40 \mathrm{~mm} \times 160 \mathrm{~mm}$. The loading rate is $500 \mathrm{~N} / \mathrm{s}$ and the test temperature is $20^{\circ} \mathrm{C}$. Three samples with different bitumen emulsion content were selected for each group and the average of the three specimens was adopted as the strength value of each group.

2.3.3. Viscoelastic Property Tests. The viscoelastic property of the CBEM was tested by the DMA-Q800 dynamic mechanical analyzer. The $35 \mathrm{~mm} \times 15 \mathrm{~mm} \times 5 \mathrm{~mm}$ specimens with 28-day curing ages were used according to the size of the double cantilever mold. The test amplitude was set to $15 \mu \mathrm{m}$ and the test temperature was $25^{\circ} \mathrm{C}$. The viscoelastic property of CBEM at 24 frequency points from $0.0 \mathrm{~Hz}$ to $12.0 \mathrm{~Hz}$ was tested.

The DMA method is always used to test the viscoelastic property of materials. When the material has viscoelastic property, the deformation lags behind the applied load and there is a phase difference between the load and the deformation. Generally, the complex constant modulus is defined as

$$
E^{*}=\frac{\sigma}{\varepsilon}=\frac{\sigma_{0}}{\varepsilon_{0}}(\cos \varphi+i \sin \varphi)=E(\cos \varphi+i \sin \varphi),
$$

where $E^{*}$ represents the complex modulus of the material; $\sigma$ represents the stress of the material; $\varepsilon$ represents the strain generated after the material is stressed; and $\varphi$ represents the phase angle.

Compared with the general elastic complex modulus definition

$$
E^{*}=E^{\prime}+i E^{\prime}=E^{\prime}(1+i \eta)
$$

it can get that as equations (3), (4), and (5):

$$
\begin{gathered}
E^{\prime}=E \cos \varphi, \\
E^{\prime \prime}=E \sin \varphi, \\
\eta=\tan \varphi=\frac{E \sin \varphi}{E \cos \varphi}=\frac{E^{\prime \prime}}{E^{\prime}} .
\end{gathered}
$$

The loss factor $\eta$, which represents the viscoelastic property of the material, is an important parameter that represents the material's ability to dissipate.

2.3.4. XRD Analyses. CBEM with 50\% bitumen emulsion and cement mortars without bitumen emulsion were used for the XRD test. The specimens were selected for the curing of 28 days. After the sample was crushed, an appropriate amount of small particles was used and fully ground into powder (up to $0.063 \mathrm{~mm}$ ). The ground powder was used in the XRD test. The test temperature is $20^{\circ} \mathrm{C}$, the test angle is $0-90^{\circ}$, the voltage is $40 \mathrm{kV}$, and the current is $30 \mathrm{~mA}$.

\section{Results}

3.1. Influences of Bitumen Emulsion on CBEM Workability. As shown in Figure 2, the average fluidity of CBEM without bitumen emulsion is $209 \mathrm{~s}$, and the fluidity of CBEM mixed with $50 \%$ bitumen emulsion increases to $102 \mathrm{~s}(\mathrm{ABE})$ and 99S (CBE), respectively, which is $52 \%$ higher than that of the control group. With the increase of bitumen emulsion content, the growth rate of fluidity decreased. The results showed that the fluidity of CBEM increased with the increase of bitumen emulsion content. Compared with CBEM prepared by $\mathrm{ABE}$, the fluidity of CBEM prepared by $\mathrm{CBE}$ is better. Figure 3 shows the influences of bitumen emulsion content on CBEM extensibility. It can be seen from Figure 3 that the extensibility of CBEM can be improved by adding bitumen emulsion. It increases to $308 \mathrm{~mm}$ (CBE) and $316 \mathrm{~mm}$ (ABE) from $240 \mathrm{~mm}$, and bitumen emulsion content has no significant influence on the extensibility of the CBEM. The addition of bitumen emulsion can effectively improve the extensibility of the CBEM and the influence of the emulsifier types is not significant. The extensibility of CBEM was more than $280 \mathrm{~mm}$. 


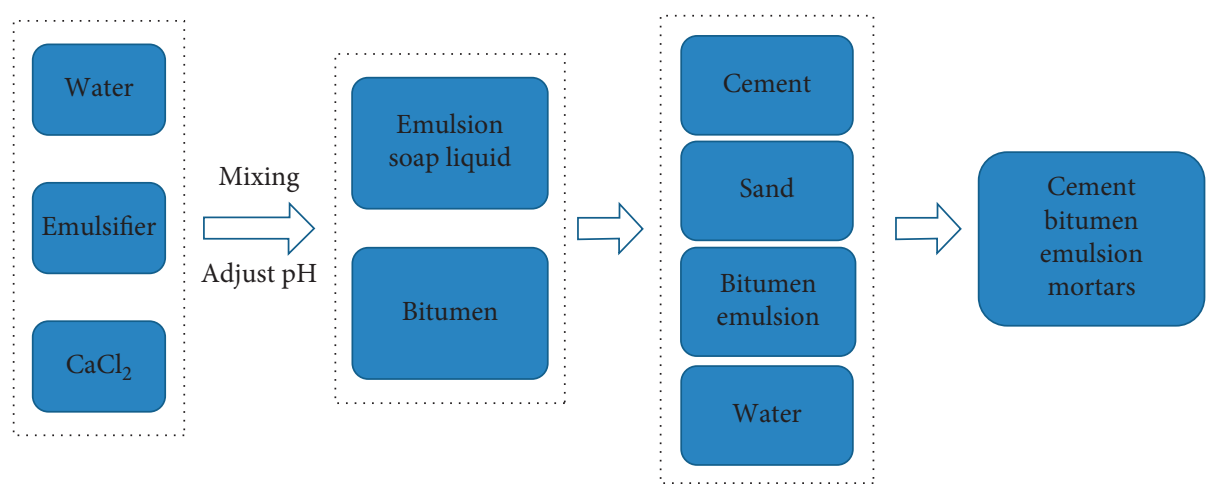

Figure 1: Flowchart of CBEM preparation.

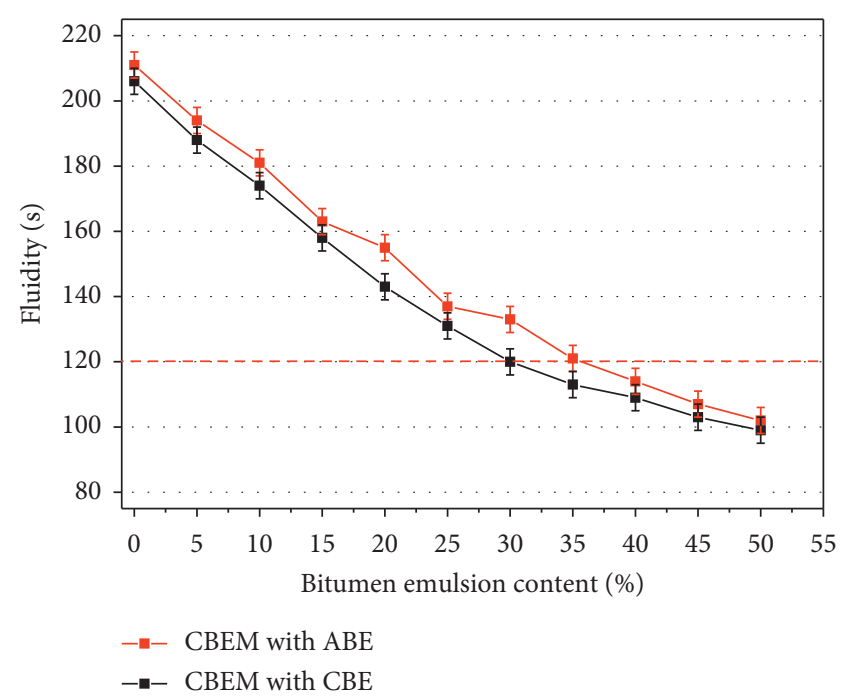

Figure 2: Influences of bitumen emulsion content on CBEM fluidity.

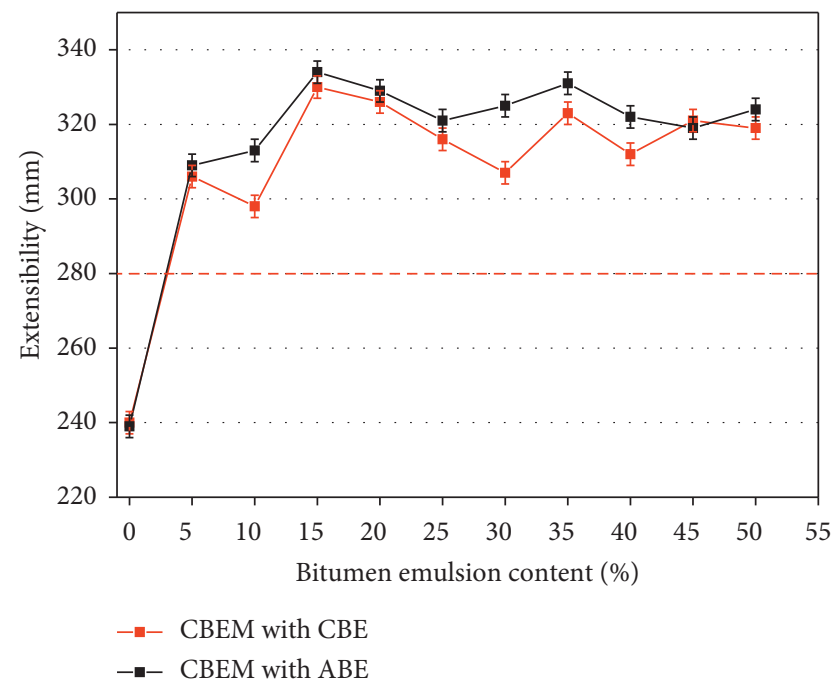

FIgURE 3: Influences of bitumen emulsion content on CBEM extensibility.
3.2. Influences of Bitumen Emulsion on CBEM Mechanical Properties. As shown in Figures 4 and 5, it can be seen that adding bitumen emulsion can significantly reduce the compressive and flexural strength of CBEM in the early 3 and 7 days. It also can reduce the compressive and flexural strength of CBEM at 28-day curing age. The higher the content of the bitumen emulsion is, the greater the strength loss of CBEM can be. With the increase of cationic bitumen emulsion content, the compressive strength of CBEM is decreased by $63.9 \%, 43.7 \%$, and $44.1 \%$ in $3 \mathrm{~d}, 7 \mathrm{~d}$, and $28 \mathrm{~d}$, respectively. With the increase of $\mathrm{ABE}$ content, the compressive strength of CBEM is decreased by $51.8 \%, 33.3 \%$, and $39.0 \%$ in $3 \mathrm{~d}, 7 \mathrm{~d}$, and $28 \mathrm{~d}$, respectively.

With the increase of cationic bitumen emulsion content, the flexural strength of CBEM is decreased by $60.9 \%, 55.3 \%$, and $40.6 \%$ in $3 \mathrm{~d}, 7 \mathrm{~d}$, and $28 \mathrm{~d}$, respectively. With the increase of $\mathrm{ABE}$ content, the flexural strength of CBEM is decreased by $63.4 \%, 57.4 \%$, and $44.0 \%$ at $3 \mathrm{~d}, 7 \mathrm{~d}$, and $28 \mathrm{~d}$, respectively. The strength loss of CBEM prepared by $\mathrm{CBE}$ is lower than that of CBEM prepared by ABE.

Hydration of tricalcium silicate produces hydrated calcium silicate and calcium hydroxide. The chemistry reaction equation is shown in

$$
\begin{aligned}
3 \mathrm{CaO} \cdot \mathrm{SiO}_{2}+n \mathrm{H}_{2} \mathrm{O}= & x \cdot \mathrm{CaO} \cdot \mathrm{SiO}_{2} \cdot y \cdot \mathrm{H}_{2} \mathrm{O} \\
& +(3-x) \mathrm{Ca}(\mathrm{OH})_{2} .
\end{aligned}
$$

As shown in Figure 6, the XRD result shows that the tricalcium silicate phase, limestone phase, and hydrated lime phase appeared in the CBEM materials after bitumen emulsion demulsification and cement hydration. It shows that there is no chemical reaction between bitumen and cement as an inert admixture and no new mineral phase is formed. Compared with the cement mortars without bitumen emulsion, the addition of bitumen emulsion cannot change the type of cement hydration products.

\subsection{Viscoelastic Property of CBEM}

3.3.1. Influences of Bitumen Emulsion Types. In this work, two groups of different types of emulsifier with bitumen emulsion content of $50 \%$ were selected for the DMA test. As 


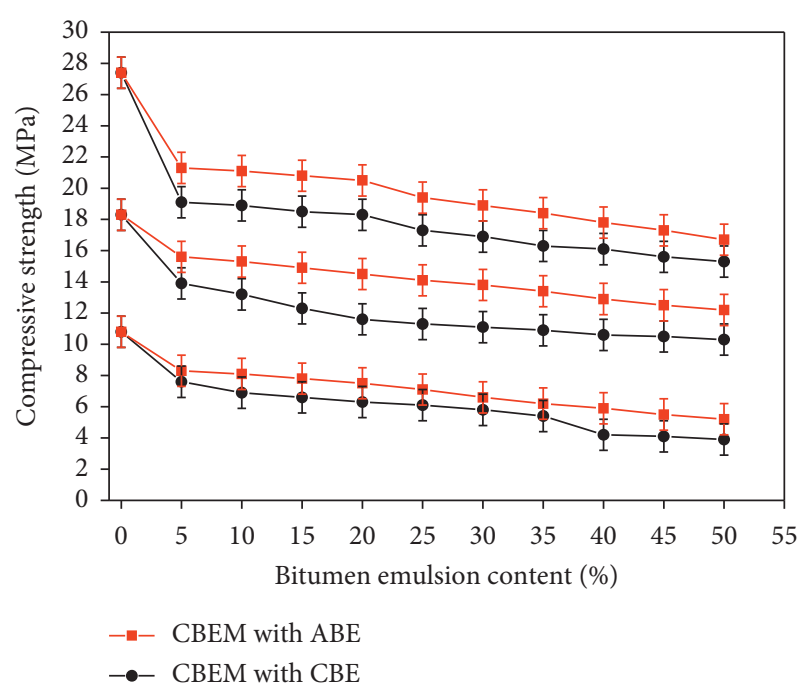

Figure 4: Influences of bitumen emulsion content on the compressive strength.

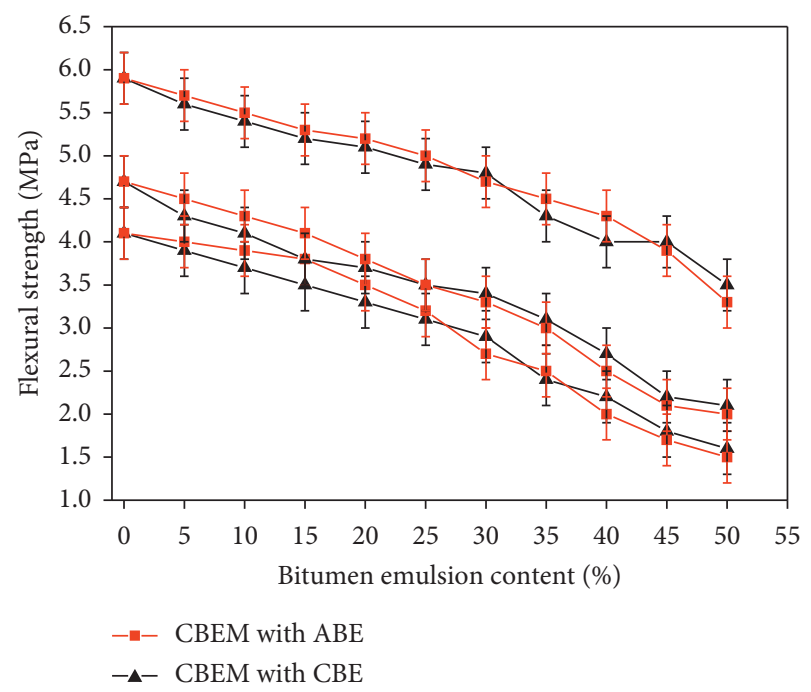

FIGURE 5: Influences of bitumen emulsion content on the flexural strength.

shown in Figure 7, with the increase of frequency, the loss factor $\eta$ of CBEM decreases. The loss factor of the CBEM prepared with $\mathrm{CBE}$ and the 50\% bitumen emulsion dosage group is 0.120 , which is 3 times higher than that of the control group. Under the same amount of bitumen emulsion, the loss factor $\eta$ at $12.0 \mathrm{~Hz}$ is 0.094 , which is $21 \%$ lower than that at $0.5 \mathrm{~Hz}$. The loss factor of the CBEM prepared with $\mathrm{ABE}$ and the $50 \%$ bitumen emulsion dosage group is 0.129 , which is 3.5 times higher than that of the control group. Under the same amount of bitumen emulsion, the loss factor $\eta$ at $12.0 \mathrm{~Hz}$ is 0.117 , which is $9 \%$ lower than that at $0.5 \mathrm{~Hz}$.

The complex modulus $E^{*}$ can be used to characterize the viscoelastic property of materials. Among them, the real part of the complex modulus represents the strain energy of the material, which is the storage modulus $E^{\prime}$. The imaginary part of the complex modulus represents the thermal energy of the material, namely, the loss modulus $E^{\prime \prime}$. Therefore, the viscoelastic property of the material is positively related to the loss factor. With the increase of the loss factor, the dissipation capacity of the material increases, and the viscoelastic property of the material is better. Therefore, it can be seen from Figure 7 that the viscoelastic property of CBEM prepared by $\mathrm{ABE}$ is better than that of CBEM prepared by CBE.

\subsubsection{Influences of Bitumen Emulsion Dosage and Frequency.} As shown in Figures 8 and 9, in contrast to the control group, the loss factor of CBEM can be significantly improved by adding a different amount of bitumen emulsion. The loss factor $\eta$ of CBEM prepared with CBE increased from 0.039 to $0.059,0.063,0.058,0.064,0.070,0.083,0.088,0.092,0.097$, and 0.107 . When the bitumen emulsion content was 0.107 , the maximum increase of loss factor $\eta$ was $64 \%$. The loss factor $\eta$ of CBEM prepared with ABE increased from 0.039 to $0.066,0.069,0.072,0.077,0.084,0.093,0.101,0.109,0.114$, and 0.118 . When the bitumen emulsion content was 0.118 , the maximum increase of loss factor $\eta$ was $67 \%$. At the same frequency, the loss factor $\eta$ of CBEM increases with the increase of bitumen emulsion content, and the energy dissipation capacity of the material increases.

The results are influenced by the frequency and the loss factor $\eta$ values of each group decrease by $18 \%$ and $12 \%$. High frequency causes CBEM to deform more and the CBEM needs to convert this part of the deformation into heat energy through its own energy consumption to dissipate the energy. With the increase of vibration frequency, the energy consumption increases, and the energy consumption capacity of materials decreases. Therefore, under high frequency, the viscoelastic property of the material is not as good as that of the low frequency.

\section{Discussion}

4.1. Reason Analyses for Bitumen Emulsion on CBEM Workability. CBEM can be regarded as the coexistence system of bitumen emulsion and cement mortars. Because of the particle size of cement and sand and the double action of interfacial film and interfacial charge layer, the CBEM system has good stability. When the dry materials and bitumen emulsion just contacted, the system is still in a relatively stable state. Figure 10 shows the influence of bitumen emulsion on CBEM workability. Figure 10(a) shows dispersion distribution of cement, sand, bitumen particles, and emulsifier molecules. When the dry materials contacted with bitumen emulsion, the hydration reaction of cement with water can produce a large number of $\mathrm{Ca}^{2}{ }^{+}, \mathrm{K}^{+}, \mathrm{Na}^{+}, \mathrm{OH}^{-}$, $\mathrm{SO}_{4}{ }^{2-}$, and $\mathrm{HSO}_{3}^{-}$plasma, attracting the surrounding free emulsifier molecules (Figure 10(b)).

From 3.1 test conclusions, it is known that the fluidity and extensibility of CBEM can be improved by bitumen emulsion and the fluidity of CBEM is influenced by the bitumen emulsion dosage. The main reason is that when the molecular content of free emulsifier is low, the cement 


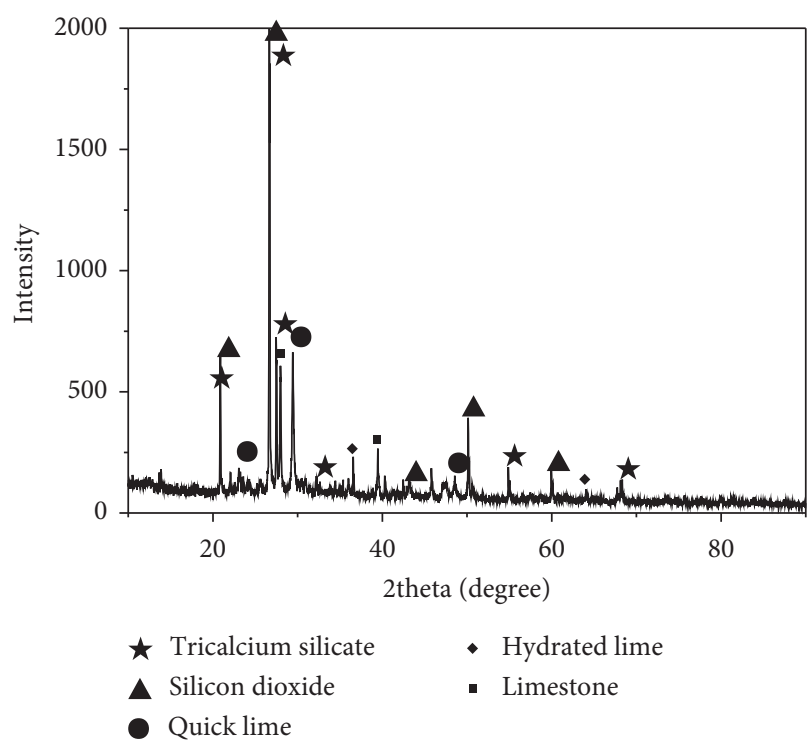

(a)

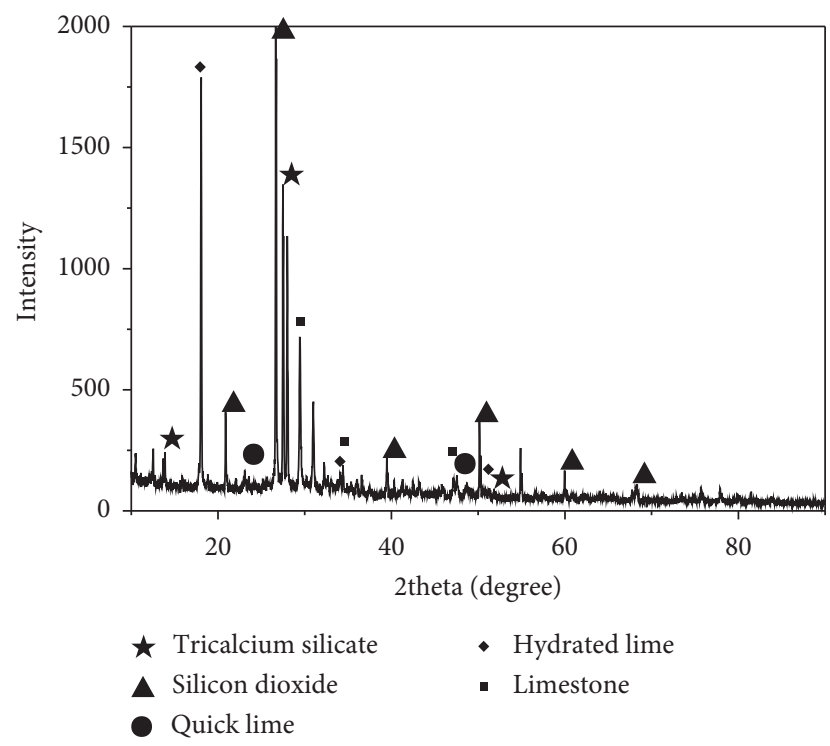

(b)

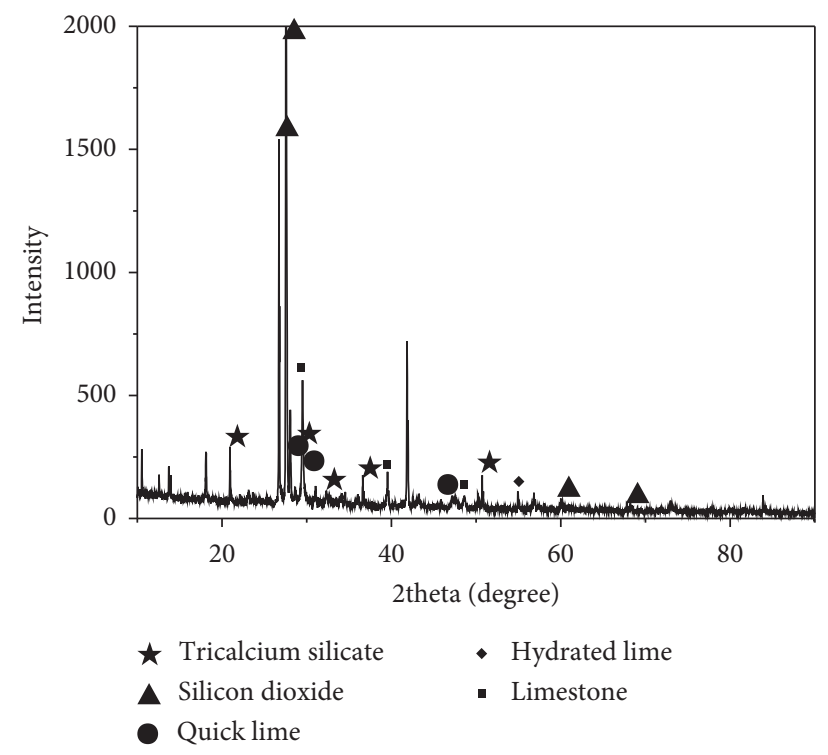

(c)

Figure 6: XRD pattern of CBEM: (a) without bitumen emulsion; (b) with ABE; (c) with CBE.

particles begin to absorb bitumen emulsion around the cement particles (Figure 10(c)). Due to the reduction of free water in the system caused by cement hydration reaction and the adsorption of cement particles on bitumen emulsion, the mortars can gradually lose stability and demulsification and condensation occurred on the surface of cement particles. The hydration of cement particles and water is prevented and the volume fraction of the continuous phase is not decreased. Thus, the increase of internal friction between dispersed phases in CBEM is prevented and the fluidity of CBEM is improved (Figure 10(d)).

4.2. Reason Analyses for Emulsifier Types on CBEM Workability. The cationic emulsifiers are the main derivatives of an organic amine. The molecular structure of the cationic bitumen emulsifier used in this work is shown in Figure 11. When the dry materials are mixed with CBE, the nitrogen atom in the cationic emulsifier has strong adsorption and affinity with the acid alkali aggregate, which can pull the bitumen emulsion bead particles to the surface of the dry materials. As the cement hydration, the pressure between the emulsifier molecules and the dry materials can squeeze the water from the two and this process can make the bitumen form a film between the cement hydration product and the gravel. At the same time, due to the positive charge of the cationic emulsifier and the negative charge of the particles after the cement hydration, the bitumen particles are easily adsorbed on the surface of the cement particles. CBE is faster in demulsification, condensation, and molding, so the water consumption of CBEM prepared by 


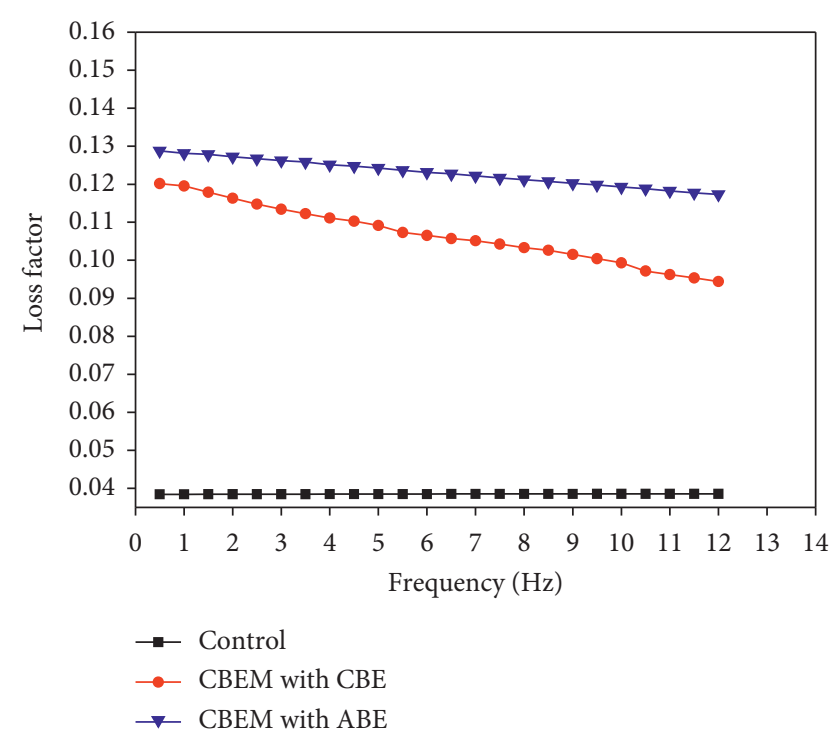

Figure 7: Influences of bitumen emulsion on CBEM viscoelastic property.

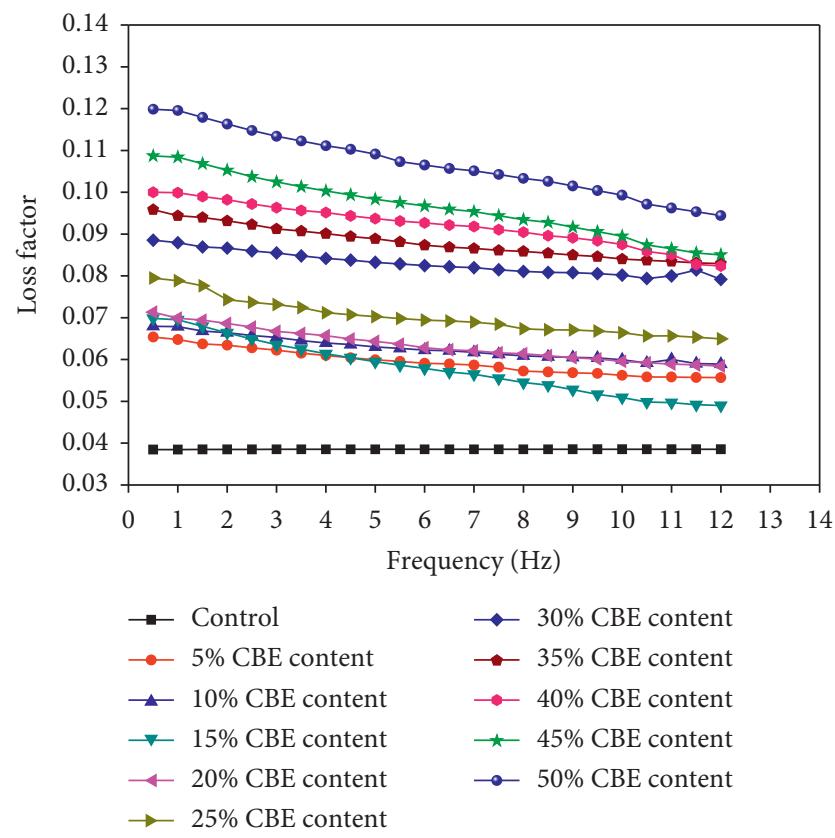

FIgURE 8: Influences of CBE content on the viscoelastic property.

CBE is less. The improvement of the fluidity of CBEM prepared by CBE is better than that of CBEM prepared by ABE. The experimental conclusions of 3.1 are verified.

The lipophilic group of the anionic emulsifier molecular is the same as the cationic emulsifier, but the hydrophobic group contains many oxygen atoms except the sulfur atom and the carbon atom. The molecular structure of the anionic bitumen emulsifier used in this work is shown in Figure 12. When the dry materials are mixed with $\mathrm{ABE}$, the affinity and adsorption of the oxygen, sulfur, and carbon atoms of the hydrophilic group of the anionic emulsifier with the dry materials are worse compared with the

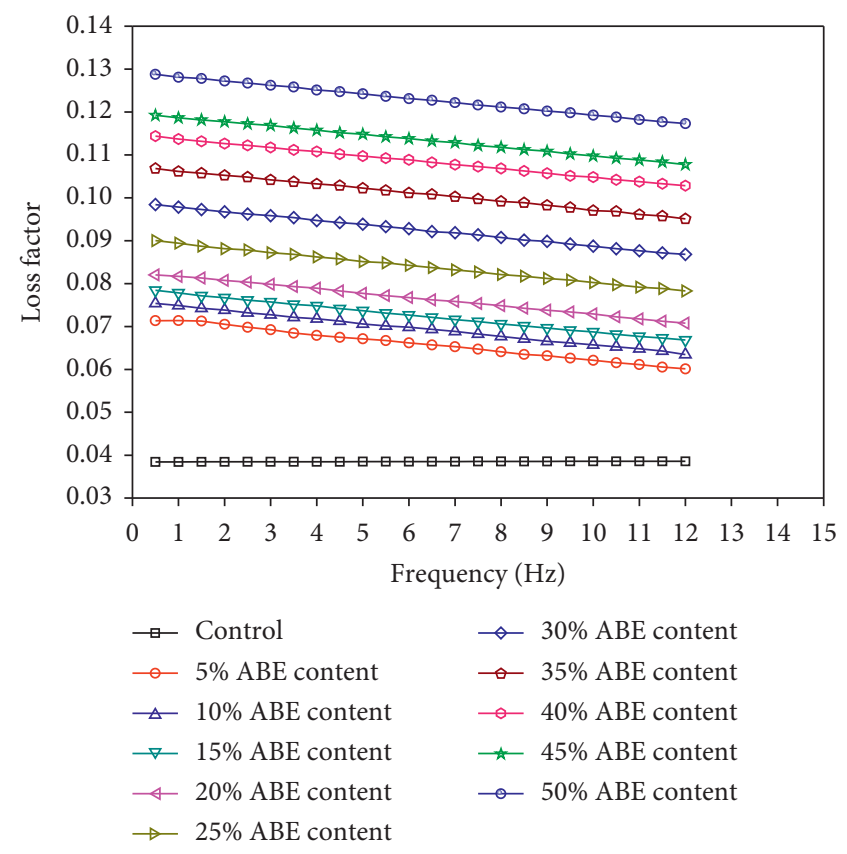

FIGURE 9: Influences of ABE content on the viscoelastic property.

nitrogen atoms in the hydrophilic group of the cationic emulsifier molecule. At the same time, the oxygen atoms in the hydrophilic group adsorb the hydrogen atoms in the water molecules and form a large number of hydrogen bonds in the bitumen emulsion. The combination of hydrogen bonds and water molecules occupies a large space, which makes it difficult for emulsifier molecules to contact the surface of dry materials directly. The aqueous phase between the bitumen emulsion and the cement hydration products cannot be easily squeezed out.

At the same time, because the particles after hydration of anionic emulsifier and cement had a large number of negative charges, bitumen and aggregate repelled each other, which makes it difficult to get close to bitumen and aggregate and hinder the demulsification of bitumen. The hydrogen bonding water of the hydrophilic group of the anionic emulsifier molecules is relatively strong and the water volatilizes at a slow speed, which results in the fact that the bitumen film cannot wrap up the dry materials in a short time. Therefore, in contrast to cationic emulsifier, the improvement of CBEM fluidity by anionic emulsifier is not as good as that by cationic emulsifier.

4.3. Reason Analyses for Mechanical Property Changes. Due to the addition of bitumen emulsion, the hydration of some cement particles is hindered. The water after demulsification of bitumen emulsion contacts with cement particles, which makes the hydration reaction continue. When the demulsification process of bitumen emulsion reaches a certain process, the bitumen emulsion penetrates between the cement particles and the hydration products, and the cement hydration process is hindered. This is why the compressive strength of CBEM at different ages after the addition of bitumen emulsion in Figure 4 is significantly 


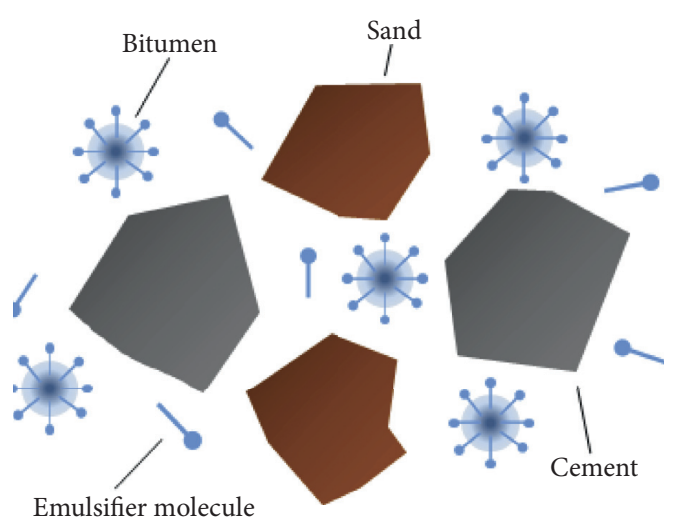

(a)

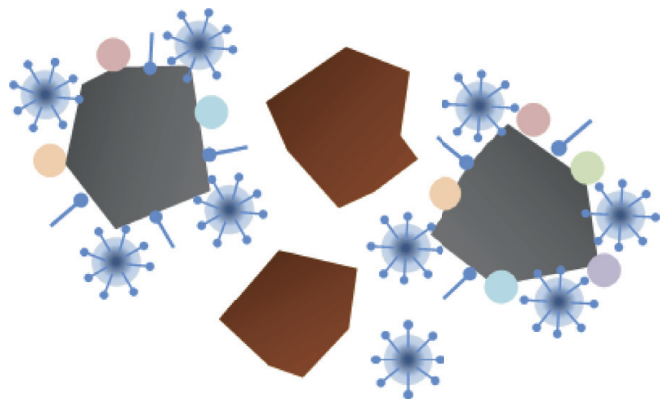

(c)

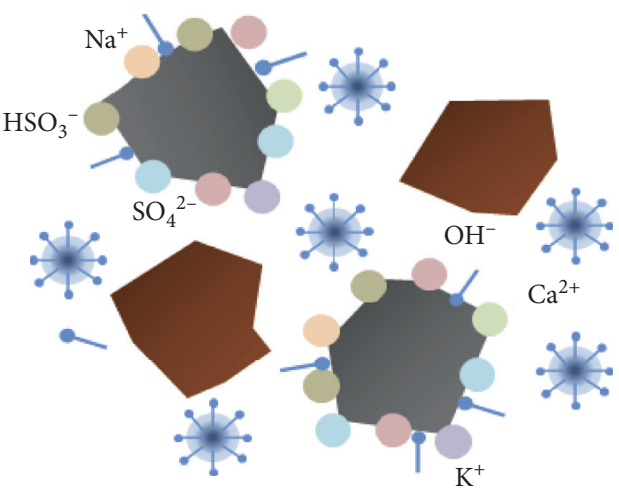

(b)

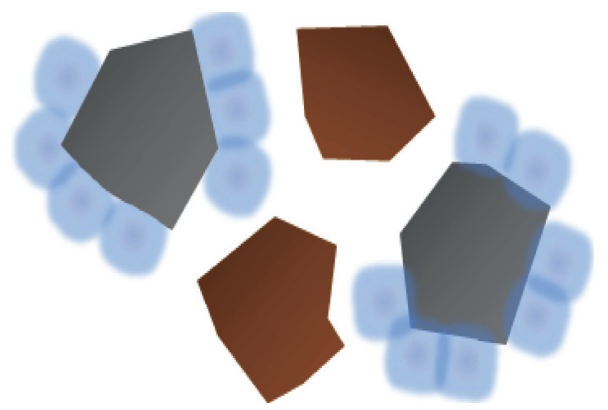

(d)

FIGURE 10: Influences of bitumen emulsion on CBEM workability: (a) contact stage; (b) prereaction stage; (c) late stage of reaction; (d) demulsification and coagulation stage.

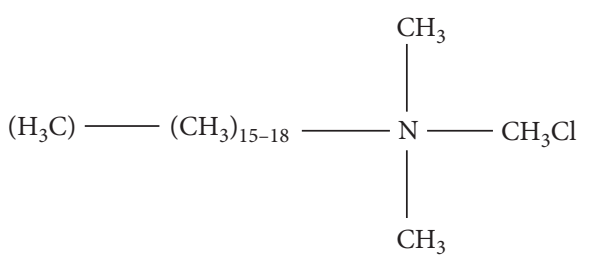

FIgURE 11: Quaternary ammonium salt.

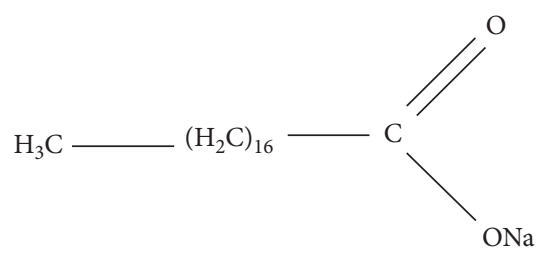

FIgURE 12: Sodium hexadecyl acetate.

reduced. The interaction of the entire cement hydrationbitumen demulsification causes the mechanical strength of the CBEM to be reduced, and the compressive and flexural strength is decreased correspondingly.

4.4. Reason Analyses for Viscoelastic Property Changes. Because the CBEM with anion has a poor affinity to the aggregate surface and has no influence on activating aggregate, the adhesion between $\mathrm{ABE}$ and dry materials depends on the adhesion between bitumen itself and dry materials. The addition of cement in CBEM improves the alkaline component of the mortars and makes the aggregate alkaline [36]. As shown in Figure 13, because the bitumen contains acid active groups, such as carboxyl, anhydrides, and phenols, it can react with $\mathrm{Ca}^{2+}$ and $\mathrm{Mg}^{2+}$ on the surface of aggregate to form water-insoluble organic acid salts. Through the organic acid salt, the cement hydrate surface is formed as a chemical adsorption layer, which can tightly absorb the cement hydration product and bitumen together, greatly enhancing the adhesion between them [37]. When CBEM with anion is completely demulsified, the bitumen emulsion fills the pores of CBEM. The bitumen emulsion is interwoven with hydration products to form a network structure after demulsification. The deformation ability of CBEM is improved, so the viscoelastic property of CBEM is improved.

For CBEM prepared by CBE, there is no evident chemical reaction between CBE and dry materials, so there is no chemical adsorption between bitumen emulsion and cement hydration products. After demulsification, most of the hydration reaction of cement has been completed, and the ion concentration is greatly reduced. Therefore, the adsorption between bitumen and cement hydration products is only physical adsorption or molecular directed adsorption. Because the influence of chemical adsorption is better than that of physical adsorption and molecular directed adsorption, the viscoelastic property of CBEM prepared by $A B E$ is better than that of CBEM prepared by CBE. 


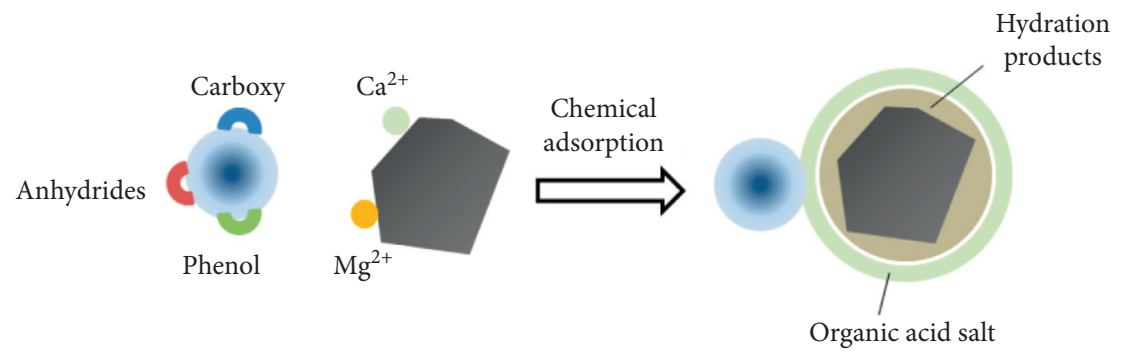

Figure 13: Chemical adsorption of CBEM by ABE.

\section{Conclusions}

In this work, the influences of emulsifier types on the workability, mechanical properties, and viscoelastic property of CBEM were systematically investigated. The workability of CBEM was evaluated by fluidity and extensibility, the mechanical properties of CBEM were evaluated by compressive strength and flexural strength tests, and the viscoelastic property of CBEM was evaluated by DMA test. In addition, the phase of CBEM was analyzed by XRD. The following conclusions could be drawn:

(1) The addition of anionic and cationic bitumen emulsion can significantly improve the workability of CBEM. The CBEM prepared by CBE has high fluidity. When the content of bitumen emulsion is between $35 \%$ and 50\%, the CBEM possesses high workability.

(2) The addition of anionic and cationic bitumen emulsion can reduce the compressive strength and flexural strength of CBEM and adversely affect the mechanical properties. CBE has a more negative influence on the compressive strength of CBEM than ABE.

(3) The loss factor $\eta$ can reflect the viscoelastic property of CBEM. After adding the bitumen emulsion, the dissipative capacity of the CBEM was improved. The loss factor $\eta$ of two different CBEM increased by $67 \%(\mathrm{ABE})$ and $64 \%(\mathrm{CBE})$ compared with cement mortars without bitumen emulsion. The viscoelastic property of CBEM has been obviously improved.

(4) Frequency is the main factor affecting the viscoelastic property of CBEM. The loss factor $\eta$ of two different CBEM is decreased by $18 \%(\mathrm{ABE})$ and $12 \%(\mathrm{CBE})$, respectively, under when the high frequency $(12.0 \mathrm{~Hz})$ compared with the low frequency $(0.5 \mathrm{~Hz})$. In high frequency, the loss factor $\eta$ loss rate is reduced by $9 \%$, while the influence of frequency on the loss factor is low. The viscoelastic property of CBEM is improved obviously.

(5) The viscoelastic property and mechanical properties of CBEM should be considered according to different needs in practical engineering. CBEM prepared by CBE has better workability, while CBEM prepared by $\mathrm{ABE}$ has better mechanical properties and viscoelastic properties.

\section{Data Availability}

The data used to support the findings of this study are included within the article.

\section{Conflicts of Interest}

The authors declare that they have no conflicts of interest.

\section{Acknowledgments}

This work was supported by National Natural Science Foundation of China (no. 51978067), Science and Technology Development Project of Xinjiang Production and Construction Corps (no. 2019AB013), and Henan Transportation Science and Technology Plan Project (no. 2019J1).

\section{References}

[1] R. Li, F. Xiao, and P. Zhu, "Research progress of special emulsified asphalt for cement emulsified asphalt mortar on high-speed railway," Chemical Journal, vol. 52, no. 2, pp. 123-126, 2011.

[2] Z. Wang, N. Dai, X. Wang, G. Li, and H. Guo, "Early-stage road property improvements of cold recycled asphalt emulsion mixture with microwave technology," Journal of Cleaner Production, vol. 263, Article ID 121451, 2020.

[3] C. Chen and B. Zhan, "Study on crack resistance of CA mortar based on low temperature bending test," Journal of Hefei University of Technology (Natural Science Edition), vol. 43, no. 4, pp. 530-535, 2020.

[4] Z. Wang, X. Shu, T. Rutherford, B. Huang, and D. Clarke, "Effects of asphalt emulsion on properties of fresh cement emulsified asphalt mortar," Construction and Building Materials, vol. 75, pp. 25-30, 2015.

[5] H. Zhang, L. Meng, and G. Zhang, "Comparative study on mechanical performance of asphalt-cement mortar and emulsified asphalt-cement mortar," Road Materials and Pavement Design, vol. 18, no. 5, pp. 1239-1250, 2017.

[6] W. Li, J. Hong, X. Zhu et al., "Retardation mechanism of anionic asphalt emulsion on the hydration of Portland cement," Construction and Building Materials, vol. 163, pp. 714-723, 2018.

[7] E. Garilli, F. Autelitano, C. Godenzoni, A. Graziani, and F. Giuliani, "Early age evolution of rheological properties of over-stabilized bitumen emulsion-cement pastes," Construction and Building Materials, vol. 125, pp. 352-360, 2016.

[8] Z. Song, P. Xu, and J. Tao, "Study on demulsification mechanism of emulsified asphalt," Petroleum Asphalt, vol. 3, pp. 23-29, 1995. 
[9] M. Miljković, M. Radenberg, X. Fang, and P. Lura, "Influence of emulsifier content on cement hydration and mechanical performance of bitumen emulsion mortar," Materials and Structures, vol. 50, no. 3, p. 185, 2017.

[10] L. Kong, F. Tang, Y. Xu, P. Zhao, and Y. Zhang, "Evaluation of emulsified asphalt demulsification process by ultraviolet spectroscopy," Journal of Chang'an University: Natural Science Edition, vol. 37, no. 6, pp. 17-23, 2017.

[11] Q. Fu, Y. Xie, K. Zheng, H. Song, and X. Zhou, "Influence of asphalt on mechanical property of cement asphalt mortar," Acta Silicate Sinica, vol. 42, no. 5, pp. 642-647, 2014.

[12] X. Fang, A. Garcia, F. Winnefeld, N. Partl, and P. Lura, "Impact of rapid-hardening cements on mechanical property of cement asphalt emulsion asphalt," Materials and Structures, vol. 49, no. 1-2, pp. 487-498, 2016.

[13] M. Miljkovic, L. Poulikakos, F. Piemontese, M. Shakoorioskooie, and P. Lura, "Mechanical behaviour of bitumen emulsion-cement composites across the structural transition of the co-binder system," Construction and Building Materials, vol. 215, pp. 217-232, 2019.

[14] Q. Wang, J. Feng, and P. Yan, "Strength loss of cement asphalt mortar under outdoor natural conditions," Journal of Tsinghua University (Nature Science Edition), vol. 53, no. 1, pp. 1-5, 2013.

[15] Z. Wang, N. Dai, X. Wang, J. Zhang, and H. Guo, "Laboratory investigation on effects of microwave heating on early strength of cement bitumen emulsion mixture," Construction and Building Materials, vol. 236, 2020.

[16] J. Wang, W. Wang, and $\mathrm{X}$. Wu, "Mechanical property of cement asphalt mortar under low temperature condition," Journal of Testing and Evaluation, vol. 47, no. 3, pp. 19952009, 2019.

[17] H. Peng, Y. Zhang, J. Wang, Y. Liu, and L. Gao, "Interfacial bonding strength between cement asphalt mortar and concrete in slab track," Journal of Materials in Civil Engineering, vol. 31, no. 7, Article ID 04019107, 2019.

[18] Y. Wang, Q. Yuan, and D. Deng, "Degradation of mechanical properties of CA mortar caused by calcium leaching," Construction and Building Materials, vol. 208, pp. 613-621, 2019.

[19] X. Zeng, Y. Li, Y. Ran, K. Yang, F. Qu, and P. Wang, "Deterioration mechanism of CA mortar due to simulated acid rain," Construction and Building Materials, vol. 168, pp. 1008-1015, 2018.

[20] B. Liu and D. Liang, "Effect of mass ratio of asphalt to cement on the properties of cement modified asphalt emulsion mortar," Construction and Building Materials, vol. 134, pp. 39-43, 2017.

[21] X. She, R. Li, H. Zhang, X. Chen, and H. Deng, "Preparation and property of anionic CA mortar," Chemical Journal, vol. 53, no. 1, pp. 1-4, 2012.

[22] Q. Wang and P. Yan, "Effect of sand- ash ratio and sand-level matching on the compressive strength and fluidity of CA mortar," Journal of Railway Science and Engineering, vol. 5, no. 6, pp. 1-5, 2008.

[23] D. Li, K. Wu, G. Yang, and X. Bao, "Evaluation and analysis of factors affecting performance of cement emulsified asphalt mortar," Highway, vol. 8, pp. 212-215, 2012.

[24] J. Ren, H. Li, X. Cai, S. Deng, J. Wang, and W. Du, "Viscoelastic deformation behavior of cement and emulsified asphalt mortar in China railway track system I prefabricated slab track," Journal of Zhejiang University-Science A: Applied Physics and Engineering, vol. 21, no. 10, pp. 304-316, 2020.
[25] J. Ouyang, Y. Tan, Y. Li, and J. Zhao, "Demulsification process of asphalt emulsion in fresh cement-asphalt emulsion paste," Materials and Structures, vol. 48, no. 12, pp. 3875-3883, 2015.

[26] J. Ouyang and Y. Tan, "Rheology of fresh cement asphalt emulsion pastes," Construction and Building Materials, vol. 80, pp. 236-243, 2015.

[27] Q. Fu, Y. Xie, G. Long, D. Niu, and H. Song, "Dynamic mechanical thermo-analysis of cement and asphalt mortar," Powder Technology, vol. 313, pp. 36-43, 2017.

[28] Z. Wang, X. Xu, X. Wang, J. Huo, H. Guo, and B. Yang, "Performance of modified asphalt of rubber powder through tetraethyl orthosilicate (TEOS)," Construction and Building Materials, 2020.

[29] J. Wang, J. Ouyang, J. Zhao, Y. Tan, and Y. Li, "Viscoelastic property of CRTS II type CA mortar," Journal of China University of Petroleum: Natural Science, vol. 37, no. 4, pp. 165-168, 2013.

[30] Q. Fu, Y.-J. Xie, G.-C. Long, F. Meng, and H. Song, “Temperature sensitivity and model of stress relaxation properties of cement and asphalt mortar," Construction and Building Materials, vol. 84, pp. 1-11, 2015.

[31] X.-T. Qin, S.-Y. Zhu, S.-F. Chen, X. Li, and H.-B. Dou, "Comparative study on the deformation behaviors of cement emulsified asphalt mortars," Materials and Structures, vol. 48, no. 10, pp. 3241-3247, 2015.

[32] X. Fang, A. Garcia-Hernandez, F. Winnefeld, and P. Lura, "Influence of cement on rheology and stability of rosin emulsified anionic bitumen emulsion," Journal of Materials in Civil Engineering, vol. 28, no. 5, Article ID 04015199, 2016.

[33] J. Ouyang, H. Li, and B. Han, "The rheological properties and mechanisms of cement asphalt emulsion paste with different charge types of emulsion," Construction and Building Materials, vol. 147, pp. 566-575, 2017.

[34] Z. Wang and A. Sha, "Microstructure characteristics of cement emulsified asphalt composite mastic," Journal of Chang'an University: Natural Science Edition, vol. 29, no. 5, pp. 11-14, 2009.

[35] Ministry of Railways of the People's Republic of China, Instructions for Type II Cement Emulsified Asphalt Mortar, Ministry of Railways of the People's Republic of China, Beijing, China, 2008.

[36] T. Oey, E. C. La Plante, G. Falzone et al., "Calcium nitrate: a chemical admixture to inhibit aggregate dissolution and mitigate expansion caused by alkali-silica reaction," Cement and Concrete Composites, vol. 110, Article ID 103592, 2020.

[37] Z. Wang, P. Wang, H. Guo, X. Wang, and G. Li, "Adhesion improvement between RAP and emulsified asphalt by modifying the surface characteristics of RAP," Advances in Materials Science and Engineering, vol. 2020, Article ID 4545971, 2020. 